\title{
Bypassing the Technocratic State in South Korea
}

\section{Doctors Mobilizing Korean Medicine in the COVID-19 Pandemic of 2020}

\author{
James Flowers | ORCID: 0000-0003-2361-119x \\ Brain Pool Program Research Fellow, Industry-Academic Cooperation \\ Foundation, Kyung Hee University, Seoul, South Korea \\ jimflowers@khu.ac.kr
}

\begin{abstract}
This article reveals an important, yet hidden, Korean response to the CoviD-19 pandemic in 2020 that goes beyond the actions of the state. It focuses on the Korean medicine doctors who were excluded from any government-led public health or treatment plans for COVID-19. Bypassing the state, they used telehealth to provide herbal medicines to 20 percent of COVID-19 patients in South Korea. Traditional medicine doctors volunteered their services and financial resources to fill a gap in COVID-19 care. Most observers attribute Korean success in controlling COVID-19 to the leadership of the technocratic state with buy-in from the population. However, the case of Korea offers an example of bottom-up healthcare in a community where people chose their own native cultural resources and helps to explain how doctors were able to take the initiative to autonomously work with people in the community to help to stop the otherwise rapid transmission of the virus.
\end{abstract}

\section{Keywords}

Korean medicine - COVID-19 - telemedicine - alternative to state technocratism psychological healing

On June 17, 2020, a small group of Association of Korean Medicine (АКОМ) leading figures participated in a policy forum in the Korean National Assembly Building in Yoŭido, central Seoul, to discuss the application, response, and implementation of Korean medicine in the future post-COVID-19 South Korea. As well as thinking about a postpandemic future, they were signaling the success of Korean medicine doctors' role in providing treatments to a substantial 
proportion of COVID-19 patients in Korea in the previous three months. A group photo of the event shows nearly all of the fifteen men and two women gazing sternly ahead, perhaps fitting for the gravity of the health crisis that had afflicted Korea earlier in 2020. National Assembly members, including Min Hyung-bae, Jin Sung-joon, and Yoon Jae-kab, all representatives of the ruling Democratic Party of Korea, co-hosted the meeting with Aком Chair, Ch'oe Hyŏk-yung. ${ }^{1}$ Korean medicine doctors making their case to the Assemblymen to better support Korean medicine in the long term included Ko Seong-Gyu, Professor of Preventive Medicine at the College of Korean Medicine in Kyung Hee University in Seoul, and Choi Seung-hoon, who had been the Officer for Traditional Medicine in the World Health Organization Western Pacific Region during the SARs (Severe Acute Respiratory Syndrome) crisis of 2003. ${ }^{2}$ Thus Choi brought his experience in the administration of an earlier pandemic to express his confidence in Korean medicine's important role in the CoviD-19 crisis of 2020.

Although the doctors ${ }^{3}$ argued their case in the halls of the National Assembly, a locus of political power, for their place in the official medical infrastructure of post-COVID-19 Korea, their actions as medical professionals who played an important role in curing many CoviD-19 patients have drawn little attention both domestically and globally in the news media and among medical and healthcare communities. Although a meeting with Assemblymen may be potentially consequential, the ruling Moon Jae-in administration had not included Korean medicine in its plans to deal with the CoviD-19 pandemic in 2020. Such marginalization of Korean medicine sharply contrasts with the Chinese (People's Republic of China, PRC) state's eventual bellicose lionizing of Chinese medicine as a key "magic weapon" in a war to eliminate the covid19 virus from China. ${ }^{4}$ The Beijing authorities aggressively promoted a top-down version of Chinese medicine. Some news outlets even reported that the state demanded that people in various institutions consume standardized herbal drinks. ${ }^{5}$ The PRC state's triumphant months-long drumbeat of the extraordinary benefits of Chinese medicine culminated in a lavish ceremony in Beijing's Great Hall of the People on September 8, 2020, when Communist Party leader Xi Jinping anointed People's Hero status on a small number of doctors, but most prominently Scottish-trained pulmonologist Zhong Nanshan 钟南山 and

1 Kim 2020. This report announces that the forum will take place.

2 WHO 2004.

3 As this essay focuses on Korean medicine, my use of the term "doctors," by default, means Korean medicine doctors, licensed and recognized by the state.

4 PRC SCIO 2020. For a typical news report see Xinhua News $2020 a$.

5 Dake Kang 2020. 
President of Tianjin University of Traditional Chinese Medicine Zhang Boli 张 伯礼 by proclaiming them as leaders of a successful campaign against the virus in China. ${ }^{6}$

In the contrasting Korean case, doctors remain anonymous, with most analysts attributing success in the fight against the COvID-19 virus to the state's effective implementation of public health measures such as testing, contact tracing, quarantine, and biomedical treatment, together with buy-in from a populace that understands the need for measures such as wearing masks and social distancing. ${ }^{7}$ In this article, I argue that, beyond state-centric analyses, better understanding of the Korean case requires acknowledging the bottomup use of Korean medicine to cure and to strengthen COVID-19 patients' bodies and minds. ${ }^{8}$ This availability of Korean medicine came to fruition because of the decision of Korean medicine doctors, as a professional body, to volunteer their medical services and to distribute herbal medicines free of charge. Thus, unlike the PRC state's presentation of Chinese medicine doctors as heroic icons, Korean medicine doctors in Korea worked to help CoviD-19 patients under their own direction with little to no fanfare. As scholars, if we place the state at the center of our analyses, we may miss more important stories in which people bypass the state in making independent decisions to take responsibility for healthcare. I am not arguing that the Moon administration's healthcare strategies on COVID-19 failed. They have not. But I do argue that most commentators leave out a key dimension in understanding Korean measures in the midst of the crisis. The Korean state-led narrative privileges technocratic solutions, visibly under the leadership of Jung Eun-kyeong, commissioner of the Korea Disease Control and Prevention Agency. ${ }^{9}$ However, evidence shows that many Koreans also turned to their own native cultural resources, specifically in the form of Korean medicine. Furthermore, in contrast to the PRC story of great doctors as heroes, the Korean case, in the absence of state-led nationalist

6 Cao 202O. Zhong Nanshan acted as the lead doctor in China in both the SARS and coviD-19 crises. Relevant to this essay, even though he is a Western medicine doctor, in June 2020 he endorsed the Chinese medicine Lianhua Qingwen capsules to speed up patients' recovery. Zhang Boli acted as the lead Chinese medicine doctor in China in both the SARS and coviD19 outbreaks.

7 Park and Chung 2021; DiMoia 2020a, 202ob; Cha 2020, 33-5o.

8 Kim 2017, 75-93. Kim convincingly argues that most doctors of Korean medicine in South Korea practice a wide range of eclectic styles that draw on a variety of autonomous lineages and locally derived traditions. While a small number of doctors negotiate with and sometimes join state-run medical structures, most doctors maintain styles of practice over which the state has little jurisdiction.

9 Moon 2020. 
hubris, reflects a more authentic story of doctors treating CoviD-19 patients at the grassroots level, where healing is practiced as the art of quiet compassion..$^{10}$

In this article, I first provide some historical context on Koreans using herbal medicines in treating epidemic diseases. I then discuss the phenomenon of doctors mobilizing themselves and insisting that they play a role in treating COVID-19 patients. Finally, to better understand the clinical process, I draw on the experiences of four doctors. I purposely chose to focus on younger doctors at the beginning of their careers so as to avoid the easy temptation of highlighting famous doctors who sometimes hew to the default of speaking in guarded political terms. Thus I hoped to illuminate some representative voices of grassroots doctors who hold no organizational or official posts.

It is important to first clarify the term "Korean medicine." ${ }^{11}$ I use the actors' category translated from Korean Hanúihak 韓醫學, the nomenclature that only began to be widely used in the 1980s-9os. Prior to the twentieth century, Koreans knew their medicine as Eastern medicine (tongǔi 東醫) or simply medicine. Koreans continued to use the term Eastern medicine into the twentieth century, as well as the term hanbang 漢方. Although the names changed, doctors understood continuity in terms of the theoretical frameworks based on yin-yang (üm yang 陰陽), “five phases" (o haeng 五行), and $k i$ 氣 and blood. Using these concepts to understand the body, Koreans consumed herbal medicines and took acupuncture to regulate health and to cure disease. With the introduction of Western medicine into Korea in the late nineteenth century, Koreans still widely continued to use Eastern medicine. Even with aggressive industrialization based on a focus on science and technology, including the economic take-off of the so-called Miracle on the Han River in the second half of the twentieth century, increasing numbers of Koreans chose to attend universities to become doctors of East Asian medicine. Furthermore, their social status grew as Koreans continued to value East Asian medicine as their healthcare therapy of choice. ${ }^{12}$

Continuity in patients using Korean medicine became possible from the second half of the twentieth century onward with the establishment of Korean medicine and biomedicine as two parallel systems protected and regulated by the state. Medical schools and Korean medicine schools respectively accept only the best-performing high school students into their six-year training programs followed by years of clinical residency. In line with the difficulty of gaining entry into either medical program, doctors of both biomedicine and

\footnotetext{
$10 \quad$ Kim 2017.

11 Flowers 2020.

12 Kim 2016.
} 
Korean medicine enjoy the highest level of social and financial status in Korea. Korean medicine doctors earned their prestigious reputation by mobilizing with a high level of organizational ability and acumen throughout the entire twentieth century. Related to their activism, they serve to fulfill real healthcare needs with the immense popularity of Korean medicine. For example, anyone who casts their eye across any inhabited space may easily notice the ubiquitous presence of the words Hanǔiwon (Korean medicine clinic) on large signs in almost every shopping strip or shopping area or mall, in neighborhoods in every locality, both urban and rural. With the presence of independently owned hospitals and clinics specializing in Korean medicine, such embeddedness in communities and commercial districts indicates the inescapable fact of Korean medicine as an inextricable presence in people's lives. As an example of this popularity and commercial significance, in one district in central Seoul, Dongdaemun, an area of several city blocks called Kyŏngdong Market, serves as a concentrated site of Korean medicine. Visitors find streets and buildings full of bustling clinics, pharmacies, and herb sellers at their stalls, totaling at least one thousand establishments. The unmistakable aroma of hundreds of varieties of herbs drifts in the air for several blocks as doctors and their assistants boil medicinal mixtures, grind and mill herbal ingredients, and burn an herb called moxa (artemisia) as a therapeutic procedure. Within a high-tech Korea, with its advanced and sophisticated industries and services, doctors also continue to visibly operate, with a considerable level of autonomy vis-à-vis the state, based on a thread of continuity of medical knowledge and practice that reaches back several centuries.

It is important here to note that South Korea's system differs from both China and Japan in that doctors today practice with only herbal medicines and acupuncture. Unlike the integrated medicine model in China and Japan, where doctors easily cross over and practice a form of medicine that combines Western with Chinese or Japanese Kampo medicine, that does not happen in Korea. Unusually, Western medicine doctors are forbidden to practice any form of Korean medicine. ${ }^{13}$ For example, even though Zhang Boli is glorified in China as a paragon of Chinese medicine healing, he in fact presided over a system where COVID-19 patients received integrated medicine, a combination of Western medicine therapy and Chinese herbal medicine. ${ }^{14}$ In the Korean case, the distinctive feature is that some patients who consulted doctors for CoviD-19 received only Korean medicine therapy. Thus, in addition to the bottom-up nature of Korean medicine for COVID-19, in Korea patients actually

\footnotetext{
13 Ma 2010.

14 Xinhua News 2o2ob.
} 
recovered with Korean medicine rather than with an integrated treatment. Korea therefore provides comparatively more convincing evidence with regard to the clinical efficacy of herbal medicine.

In arguing that the COVID-19 narrative in Korea needs revision, I identify three broad directions in the scholarship on CoviD-19 in East Asia. First are the works that valorize competent governance in East Asia. ${ }^{15}$ Typically in this telling, the respective governments in East Asia achieved varying levels of real success in curbing Covid-19. For example, scholars laud the South Korean state's efficiency in its drawing on experience gained in the MERS (Middle East Respiratory Syndrome) outbreak of $2015 .{ }^{16}$ The second type of analysis broadly points to the positive role of Chinese medicine in battling CoviD-19, particularly in China. ${ }^{17}$ The third type, that of doctors reporting on the Korean medicine teleclinics in Taegu and Seoul, remains mostly unnoticed outside of Korea, and even in Korea itself. ${ }^{18}$ We may notice that most analysis on COVID-19 in Korea does not reach into the pre-twentieth-century past. In this article, I would like to add Korean medicine doctors, who share a range of cultural resources, including medicine, with Japan, China, Taiwan, and Vietnam, as key actors in treating COVID-19 patients.

\section{Epidemics as Historical Norm}

Twenty-first-century epidemics, such as MERS, were just recent experiences Koreans could draw on for thinking about epidemics. Records show that Koreans suffered terribly from continuous epidemics during the second half of the Chosŏn dynasty period (1392-1910). Historians mostly cite economic factors but Don Baker suggests that epidemics played an important role in Chosŏn's population shrinking from approximately ten million in 1717 to eight million in $1852 .{ }^{19}$ The severity of negative population growth becomes starker when compared to rapid population growth in the Qing empire (1636-1911)

15 Gordon 2020; Reischauer CoviD-19 Task Force 2020a, 2020b. Jaeho Kang 2020 concedes the success of the Korean government's covid response but adds the caveat that it is a continuation of the permanent state of political emergency that rules a developing country like South Korea.

16 Park and Chung 2021; DiMoia 2020a; Harrison 2020; Bretelle-Establet 2020; Hanson 2020 all focus on China as an example of capable handling of the pandemic.

17 E.g. Li et al. 2020; Tilley 2020; Ochs and Garran 2020.

18 E.g. Kwon et al. 2020; Park et al. 2020; Kim et al. 2020; Choi and Joo 2020.

19 Baker 1990, 137, drew on estimated figures of eighteen million in $175^{\circ}$ and sixteen million in 185o. For fevers, see p. 138. Park and Donghyu 2007 have revised Baker's estimated Chosŏn population figures. 
in the same time period. Doctors in the Chosŏn dynasty period mainly wrote of fevers that produced rashes, such as scarlet fever ${ }^{20}$ However, the fevers that produced spots on the body in measles and smallpox caused many more deaths. Doctors who wrote clinical handbooks on epidemic diseases include the renowned scholar-physician Hŏ Chun 許浚 (1546-1615) who wrote on contagious rash in Ways to Avoid Epidemic Disease (Pyŏkyŏksinban 辟疫神方, 1613), ${ }^{21}$ Cho Chŏngjun 趙廷俊 who wrote Pediatrics Formulas (Kŭpyubang 及幼方, 1749) focused principally on measles, Im Sobung 任瑞鳳 who published Prescriptions for the Measles Outbreak in the Imsin Year (Imsin chinyokbang 壬申麻疫方, 1752), Yi Hon-gil 李獻吉 (active late eighteenth century) who wrote Measles Prescriptions (Majinbang 麻疹方, 1775), Yi Won-p'ung 李 元豐 (1759-?) who wrote Collected Works on Measles (Majin hwisŏng 麻疹彙 成, 1802), and Hong Sŏk-chu 洪顛周 (1774-1842) who wrote Compendium on Measles (Mabang t'onghwi 麻方統彙, 1808). ${ }^{22}$ Befitting his role as a renowned polymath, and still well known in Korea today, Chŏng Yakyong 丁若鏞 (17621836) wrote A Study to Understand Measles (Magwa hoet'ong 麻科會通, 1798). ${ }^{23}$ As an example of the fragility of young life in the Chosŏn period, Chŏng himself lost four out of six sons and two out of three daughters to childhood diseases, thus underpinning his decision to write a disease monograph on measles. ${ }^{24}$

Thus, in thinking about COVID-19 in 2020, rather than limiting Koreans' memory of epidemics to the twentieth century and the MERs trauma of the twenty-first century, historical memory arguably also extends to the regular occurrence of epidemics, mainly measles and smallpox, during the Chosŏn period. Certainly, doctors in 2020 drew on the experiences of the doctors of the past in both Korea and China to shape their clinical practice with regard to Covid-19 patients. As scholars have argued, in 2020 the Moon Jae-in administration's survival depended on an effective response to CoviD-19 in order to demonstrate responsibility and virtue in governance. ${ }^{25}$ Not only did doctors draw on the Chosŏn dynasty past, but the Moon government's aggressive public health approach consciously drew on the precedent of the reign of King Chŏngjo (正祖, 1752-180o) in 1786 and his response to an epidemic outbreak. ${ }^{26}$ The first great outbreak of hongyŏk 紅疫 (mostly equivalent to what we know of as measles) in Chosŏn had occurred in 1668. In 1707 several hundred thousand

\footnotetext{
$20 \quad$ Baker 1990, 138.

$21 \quad$ Kim et al. 2015; Baker 1990, 138.

22 For the texts in this sentence, Kim 1981, 339-47. Also Baker 1990, 138.

23 Kim 1981, 344-45; Baker 1990, 138; Setton 1997.

24 Baker 1990, 141.

25 DiMoia 2020a.

26 TK 2O2O; Shin 2O1O, 2014.
} 
people died of hongyŏk, while in 1730, 10,0oo died in Hansŏng 漢城 (Seoul) alone. In 1786 Chŏngjo responded to signs of an early outbreak by first dispatching doctors to the provinces to report back to the Palace. With the information gathered, the Palace also dispatched doctors to distribute free herbal medicines throughout the kingdom. ${ }^{27}$ Thus the Moon administration's 2020 response echoes earlier state efforts to coordinate emergency relief systems in response to epidemics. While there are similarities, Chŏngjo's patronage and promotion of extensive religious rituals to ward off disease differs from the Moon administration's clashes with religious groups in 2020, notably the Christian groups Shincheonji (Church of Jesus, Temple of the Tabernacle of the Testimony) ${ }^{28}$ and the Sarang Presbyterian (Love) Church. Attitudes of the state to Korean medicine doctors have also changed over time. According to the records, doctors during the Chosŏn reign traveled to care for epidemic patients at the behest of the crown. Some officials even complained that doctors were reluctant to care for epidemic patients. ${ }^{29}$ In 2020 , however, Korean medicine doctors flipped the narrative of doctors wary of treating contagious patients by demanding that the state allow them to provide therapies for Covid-19 patients. Reminiscent of the Korean response during the East Asian financial crisis in 1997, when South Koreans famously sacrificed precious belongings for the national good, they freely gave of their time and resources. Despite varied responses over time, epidemics have remained a constant feature in Korean life. According to extant records, healers have been treating acute infectious diseases and writing about their clinical experiences for at least 500 years. ${ }^{30}$

\section{Telemedicine in Practice}

At the beginning of March 2020 South Korea ranked second to China in numbers of Covid-19 patients. ${ }^{31}$ In response, the Blue House established centralized control of managing the epidemic. ${ }^{32}$ The story of widespread testing, mask wearing, and contact tracing is well known and has been covered extensively by scholars and commentators. ${ }^{33}$ However, much to their dismay, the

\footnotetext{
27 Shin 2014, 93.

28 See Grisafi (forthcoming).

$29 \quad$ Shin 2014, 98.

30 Varlik 2020 studies the intertwining of past and present in epidemics in the Ottoman Empire.

31 World Health Organization recorded 5766 cases in South Korea. September 19, 2020.

32 The Blue House is the residence and office of the South Korean president.

33 Park and Chung 2020.
} 
state excluded Korean medicine doctors from any plans. ${ }^{34}$ In response, they vigorously pushed back by lobbying the state to relent from its top-down technocratic and discriminatory approach. Insisting that they participate by helping COVID-19 patients, АКом opened two telemedicine centers. Unlike in other countries, notably the US and China, ${ }^{35}$ where doctors consulted patients through video screens, for the first few weeks Korean medicine doctors resorted to the older technology of the telephone to consult patients in their homes, in hospitals, and in other healthcare institutions such as nursing homes. Аком opened its first telemedicine center in the southeastern city of Daegu, an early COVID-19 epicenter in Korea, on March 9. ${ }^{36}$ Doctors based in the Daegu Haany University Korean Medicine Hospital spoke to CoviD-19 patients on the phone up to April 5. Moving to using video for some consultations, Аком opened a second telemedicine center in its headquarters in Gangseo-gu, Seoul, on March 31 and began to wind down operations at the end of May. As of May 19, 2020, a total of 477 telemedicine doctors had consulted with 2,304 first-visit patients and 9,26o returning patients. ${ }^{37} \mathrm{~A}$ total of 320 medical students had also participated by receiving and making telecalls, as well as packing and delivering medicines. They brought medicine to patients' doorsteps on a daily basis at a moment when some post office workers would not do so for fear of infection. ${ }^{38}$ In all, the patients that the two centers looked after amounted to just over 20 percent of all confirmed cases in South Korea at that time..$^{39}$

This figure of nearly 12,0oo patients may seem small compared to other countries such as the US, but the proportion is significant in that 20 percent of patients did not rely only on Western medicine and the state's medical system and instead chose native herbal medicines. ${ }^{40}$ Protocols in prescribing therapies were formulated entirely by the doctors themselves, choosing from a wide range of prepared prescriptions. Unlike in China, the South Korean state neither invested nor participated in even thinking about or supervising the therapy of the 20 percent of patients who chose herbal medicine. Arguably, the Korean case provides evidence for greater space for autonomous medical

34 Seungwon Kwon et al. 2020, 1.

35 E.g. see Jin 2020a.

36 Seungwon Kwon et al. 2020, 2. As a well-known city in the southeastern Kyǒngsang Province, Daegu continues to be identified with an intense regional connection with traditional medicine, with its doctors often claiming a particular style of practice distinct from Seoul and other regions in Korea. See Flowers 2016.

37 Hanŭi Sinmun 2020.

38 Eun-Kyoung Lee $202 \mathrm{O}$.

39 Kang Younggun, email interview with the author, August 2020.

40 Of course, patients who could not breathe or who were in danger of losing consciousness needed biomedical interventions rather than Korean medicine. 
practice than in China. Korean medicine doctors, as a group, decided on their diagnostic systems and exercised freedom in prescribing the most suitable herbal prescriptions. ${ }^{41}$

To better understand the phenomenon of the telemedicine centers in Daegu and Seoul, I interviewed four doctors, two by video and two by email. I will briefly introduce them, discuss their motivations for volunteering, and then discuss their clinical thinking and resultant therapeutic decisions. Arguably the most important characteristic of the project was the emphasis on strengthening patients' bodies and minds. There was no sense of seeking a magic bullet. The doctors made clear their emphasis on the individualization of patients. ${ }^{42}$ While differentiating symptoms and signs, their therapies helped patients to maintain a balance by reducing fevers, controlling coughs, and clearing fluids from the lungs. Then they also prevented adverse immune system shocks by strengthening and stabilizing the patient, and, importantly, calming patients suffering from anxiety, stress, and fear.

Finding themselves excluded by the state, the doctors nevertheless harnessed their sense of moral duty to autonomously act to save people's lives in the health crisis. The sense of service framed all of my interviewees' discussions of their work in the pandemic. I learned of these motivations by first interviewing through video two young doctors, Yoon Hae-chang (aged thirty years old) and Ha Dong-lim. Yoon volunteered in Taegu and later in Seoul, while Ha only worked in the Seoul center. Following my interviews with Yoon and Ha, I communicated by email with Kang Younggun (telemedicine manager) and a doctor who asked to remain anonymous, whom I will call Dr. H.

Yoon graduated in Korean medicine from Sangji University in Gangwon Province and has operated his own clinic in Daegu since 2017. To volunteer at the telemedicine center, he gave up days at his own clinic, thus losing potential income. He explained, "When Covid started in Daegu, no one knew what to do. I actually applied to the government, but they denied my application. They did not allow us to see patients. I was very disappointed."43 However, Yoon felt a great sense of relief when Аком established the telemedicine center in Daegu. Likewise, Ha gave up days in her own busy clinical practice. Not only did she give her time but she even donated funds to the telemedicine center, despite being a doctoral student in the history of medicine at the College of

\footnotetext{
41 AKOM 2020.

42 Allen and Finegold 2020 argue for individualizing patients by practicing precision medicine as the best approach to treat CoviD-19 patients, but unsurprisingly they do not mention Korean medicine or Chinese medicine.

43 Dr. Yoon and I used English for the interview.
} 
Korean Medicine in Kyung Hee University in Seoul in the final weeks of writing up her thesis.

With regard to the therapies that the doctors prescribed, rather than focusing on eliminating the virus, they prescribed medicines to strengthen or balance patients' bodies, thinking in terms of $k i$, in order to mitigate the virus's potential harm. Reports show that many patients suffer from what is known as "long coviD" with a range of symptoms often including malaise, fatigue, cardiovascular disease, digestive problems, and devastating psychological symptoms such as depression, insomnia, and general anxiety. ${ }^{44}$ The AKOM doctors, including each of those that I interviewed, understand coviD-19 as a long-term problem in which patients need therapies for chronic illness and incapacitation.

Based on reports regarding CoviD-19 treatments from China, the Korean telemedicine doctors began by mostly using prescriptions to treat respiratory symptoms. Thus, using protocols borrowed from China, in the first weeks of operation, Clear the Lungs and Expel Toxins Decoction (Qingfei paidu san 清肺 排毒散) headed the list of most commonly used prescriptions. ${ }^{45}$ As the official Chinese formula to treat COVID-19, it includes more than twenty ingredients in a broad-spectrum approach designed to reduce fever, stop coughing, and relieve sore throat. Generally, many Chinese doctors had argued for using herbs with claimed antiviral and antitoxic properties such as scutellaria (huangqin 黃芩) and forsythia (lianqiao 連趐). ${ }^{46}$ Going beyond a focus on eliminating the virus, Korean doctors, though, broadened their understanding of CoviD-19 as precipitating in different patients a varied spectrum of disease states. As Yoon put it, "As time went on, we adapted and changed our approach to suit our own Korean experience." Not excessively hampered by a state that sought a form of top-down standardization of formulas, ${ }^{47}$ the doctors became more flexible and treated patients for a wider range of symptoms including many with digestive complaints such as diarrhea and vomiting, as well a high proportion of those with psychological stress. Unlike the Chinese emphasis on lung symptoms such as cough associated with pneumonia, a treatment pattern emerged in Korea of individualizing patients, thus allowing for a wider range of prescriptions, including a majority that focused on strengthening patients' ability to resist the virus. Furthermore, the doctors found that the Chinese formula Clear

44 E.g. Couzin-Frankel 2020.

45 AKOM 2020.

46 E.g. "Hubei Province Integrated Chinese/Western Medicine Hospital" 2020.

47 For a nuanced critique of the use of herbal medicine for COVID-19 in China, see Jin $202 \mathrm{Ob}$. For a typical article from China, see Luo et al. 2020. 
the Lungs and Expel Toxins Decoction caused some patients to suffer adverse side effects, such as palpitations and insomnia. ${ }^{48}$ They attributed these unfortunate events to the absence of individualization but also more importantly to the inclusion in the formula of the herb ephedra, which contains toxins and is therefore banned in many countries. ${ }^{49}$

After the initial emphasis on Clear the Lungs and Expel Toxins Decoction, the three next most commonly used prescriptions that appear in the Aком data focus on strengthening patients' bodies rather than acting as so-called antiviral medications that aim to expel toxins: Precious Jade Paste (Kyóng-ok-ko 瓊玉膏), Nourish ŭm and Strengthen the Lungs Decoction (Chaŭm pup'ei t'ang 滋陰補肺湯), and Benefit $k i$ and Strengthen the Lungs Decoction (Igki pup'ei t'ang 益氣補肺湯). ${ }^{50}$ Precious Jade Paste contains the ingredients ginseng (insam 人參), poria (pogryŏng 获苓), rehmannia (sukchihwang 地黃), and honey. In essence, this formula serves to strengthen $k i$ and blood, with no antiviral properties. Most notably, ginseng is well known as an herb that strengthens immunity and regulates the physiological systems of the body. While Nourish ŭm and Strengthen the Lungs Decoction and Benefit $k i$ and Strengthen the Lungs Decoction target treating the lungs, similarly to Precious Jade Paste, they act therapeutically by strengthening and nourishing as shown in the prescription titles.

Echoing the shift to using prescriptions that focus on strengthening or facilitating patients' bodies' ability to recover, my interviewees reinforced this therapeutic approach. Ha explained that the patients who had first taken biomedical drugs such as antivirals and antibiotics often suffered from debilitating diarrhea as a side effect. For these patients, she and many of her colleagues prescribed the well-known prescription Agastache Powder to Rectify ki (Kwak hyang chǒng ki san 蕉香正氣散) to relieve diarrhea and strengthen the digestive system. Further identifying strengthening $k i$ as crucial in therapy, Ha identified Modified Restore the Spleen Decoction (Kami kwi pi t'ang 加味歸脾湯) as her most often prescribed prescription, especially for patients with psychological problems, while Dr. H used a wide range of prescriptions but singled out Restore the Spleen Decoction (Kwi pi t'ang 歸脾湯). She related that she spoke to a sixty-seven-year-old female patient living in Daegu. Previously, the patient had consulted other doctors in the telemedicine center, who had prescribed herbs that helped her positive CoviD-19 test results turn to negative. However, she suffered from persistent insomnia. She recovered after taking

48 Beom-Joon Lee 2020.

49 Mr Lee 2011. On side effects, see Bent et al. 2003.

5 О АКОМ 2020. 
Dr. H's prescription of Restore the Spleen Decoction. One of the prescription's strengths is that it invigorates a person's health in order to enhance good quality sleep. Unlike biomedical drugs for insomnia that can dull the senses, Restore the Spleen Decoction performs the opposite effect of strengthening while simultaneously calming.

According to the renowned Chinese physician, Ma Peizhi 馬培之 (1820-1903) the spleen controls qi in general, including external physical movement. ${ }^{51} \mathrm{He}$ added that the heart controls the spirit ( $\sin$ 神). Thus, in this conceptualization, the heart and the spleen in coordination are therefore crucial to the working of all the organs since these two organs therefore cover both the physical and mental aspects of the body, being connected and interdependent. The medicinal ingredients are generally moderate and delicate. The dosages are light with little sense of a direct attack on the problem. In this medicinal formula, we see the subtle hand of physicians intent on activating the qi mechanism of the patient to activate healing.

\section{Psychological Therapy}

To supplement the simultaneous strengthening and calming effects of the herbal medicines, the Аком doctors I interviewed also made the point that psychological counseling played an important role in treating CoviD-19 patients. In other words, therapies were not limited to a pharmaceutical approach but included the recognition that helping people to achieve mental equanimity significantly aided recovery. As Yoon explained, "Many people felt scared, worried, and desperate. They felt abandoned." In a biomedical system that mostly treats the hospitalized cases with acute symptoms, the patients who were declared mild cases and asked to quarantine at home felt helpless. Yoon explained that most of the patents felt intense anxiety. "They felt the government was ignoring them. In those days, there were CoviD-19 hotlines to call, but most people could not get through. They felt they couldn't get help from anywhere. The government just told everyone to do social distancing." The image here of distressed patients with nowhere to turn for help sits at odds with the official narrative of a government apparatus that was well prepared in advance due to the MERS experience. Yoon continued: "As doctors doing telemedicine, we were able to help many people. We explained to patients how to get tested. We gave them medical information that they needed. We comforted

$5^{1}$ Chen 2006, 2297-2305. For further analysis of Restore the Spleen Decoction, see Scheid et al. 2009, 353 . 
them by spending ten minutes with each patient and five minutes out of the ten were for counseling." Subsequent to the initial period of uncertainty and even disorganization, systems began to operate more efficiently, but it is still notable that the Аком doctors are yet to receive recognition for their early efforts to fill gaps in clinical care in the face of Covid-19. They were able to help patients when hospitals could not provide the necessary therapy.

In the beginning of the crisis in Daegu, the Аком doctors were able to make diagnoses by seeing while blinded, by sharpening different diagnostic tools, especially listening and engaging patients in caring conversation. Doctors stepped up in terms of really listening to patients' voices and their breathing, understanding silences, and paying attention to every word uttered. The doctors' diagnostic vision, shifted from ocular to aural, meant that they were able to compensate for their physical absence. The healing encounter became premised on developing doctor/patient trust at a physical distance, mutually invisible, yet illuminating in terms of trust. As especially Ha and Yoon argue, the essential question was how to express empathy and to restore agency to worried and desperate patients when they were physically separated from the person they were speaking to. As all who have spent hours on Zoom will attest, audio and video communication takes a toll, making it the more remarkable that doctors volunteered their services even when already using telemedicine, which must have taken an inevitable toll. ${ }^{52}$

In thinking about the early days of COVID-19 in Korea in March 2020, it is important to also note, as Ha especially emphasized, that many of these patients were Shincheonji members. The majority of these patients were women, ${ }^{53}$ yet rather than receiving sympathy from the general public as victims of a deadly disease, they were generally stigmatized as super-spreaders. Thus marginalized in care, it is important to note that doctors did not discriminate against these patients and stepped in specifically to help them. As Ha put it, "The majority of my patients suffered from psychological problems as many of them were Shincheonji Church adherents suffering from high levels of stress. Their fears overwhelmed them, but we supported them with our medicine and by providing caring compassion. They recovered and so are very grateful to us." ${ }^{54}$ Similarly, Dr. H related that the majority of CoviD-19 patients expressed anxiety at causing a burden to others, such as family members. As Dr. $\mathrm{H}$ describes it, a significant number of doctors supplemented their herbal

$5^{2} \quad$ For historical analysis of telemedicine, see Greene, Braitberg, and Bernadett 2020.

53 Beom-Joon Lee 2020.

54 Dr. Ha spoke in Korean during the interview. I have adjusted this quotation for sense and style. 
therapies and counseling by teaching meditation and breathing exercises over the phone. ${ }^{55}$ As healthcare professionals, the Аком doctors, such as Yoon, Ha, and Dr. $\mathrm{H}$, provided free medicinal herbs but also comfort and assurance to many CoviD-19 patients who felt they could not share their anxieties with relatives and friends. ${ }^{56}$

\section{Conclusion}

In this essay, I have argued that the Korean case reveals the value of medical systems beyond the narrow frame of biomedicine that focuses on a discrete virus as causing a disease. On a broader scale, viewing health as a process opens up space for traditional medicine to play a role in prevention and recovery from illness, especially as the Korean case demonstrates for long Covid cases. Furthermore, the Korean experience reveals the importance of understanding healthcare as a social activity in which people take responsibility for their own health and bypass the medical framework designed by a technocratic state. Doctors harnessed their sense of duty and responsibility to care for their patients by circumventing the state's exclusion of them by voluntarily giving their services and donating herbal medicines free of charge. In short, the doctors did not receive pay for their work, and instead paid in terms of time and lost income to contribute to saving lives and helping people recover from Covid-19.

In terms of therapy, biomedicine doctors receive little training in medical therapies that strengthen bodies in a constitutional sense. Rather, they receive extensive training in identifying, diagnosing, and treating discrete diseases. Such skills are necessary and valuable. But in the context of long covid patients who experience general malaise and fatigue, what rehabilitative therapies can they offer? Here is where Korean medicine, or Chinese medicine, is able to make an important contribution with doctors treating patients with comorbidities arising from infectious disease. Ironically, the South Korean state's hands-off approach provided a space for Korean medicine doctors to design their own treatment protocols. We are also able to learn about their own experiences, unbound by the need to align with a directive state as in

55 Kwon and Lee 2020. Kwon 2020 refers to his treatment of patients with psychological distress as "disinfecting the mind." He means that doctors in the telemedicine center paid special attention to psychological symptoms such as worry and sadness. They employed communicative healing techniques such as relaxation and mindfulness, together with medications.

$5^{6} \quad$ For a historical study of mental health in Korea, see Yoo 2016. 
China, with the Korean practice of individualizing of patients rather than emphasizing standardized, one-size-fits-all prescriptions.

Korea offers a case of a medical system that is relatively open by default, allowing doctors of Korean medicine, for the most part, to practice as they wish, at least in the private medical marketplace, in the absence of a state apparatus that shapes their image for global consumption. Critics of Chinese medicine often argue that the opaque system of PRC political structures obviate untainted medical data and reporting, that this has a crippling impact on the reliability of trials, and that it calls into doubt the validity of published trials in PRC medical journals. ${ }^{57}$ I argue that South Korea, with its comparatively transparent information sources, offers a possible nonpolitical avenue for assessment of the value of traditional medicine. Furthermore, regarding concerns about reporting methodology, both Western and Korean critics argue that biomedical science, narrowly defined, stands as the norm by which all other healthcare systems should be judged. However, in the midst of a global health crisis with so much untold death and suffering, patients in Korea, China, and Taiwan have recovered from CoviD-19 through Korean and Chinese medicine, even while our biomedicine colleagues deem this phenomenon anecdotal evidence. ${ }^{58}$ In such a painful moment, historian of medicine Charles Rosenberg helps us to understand historically how biomedicine doctors came to think of herbal medicine as marginal. ${ }^{59}$ Seeking to establish their own form of medicine, one of many, they sought to frame themselves as of the "priesthood," meaning that they claimed a monopoly on the truth on medical matters. In Rosenberg's analysis, such boundary-setting continues to be unsustainable when the scientific facts on the ground shift in constant flux. In the case of Korea, even though the state accepts, with their actions, the institutionalization of imagined boundaries set by biomedicine doctors, actual people destabilize and dissolve the unstable bastion of biomedicine as scientific orthodoxy. In the case of COVID-19 in 2020, Korean people continue to insist on using their own cultural resources regardless of any so-called scientific imperative to seek the imprimatur of the high church of biomedicine. During the COVID-19 pandemic Korea continues to earn praise for its COVID response, which has featured only very limited lockdown measures and relatively open borders. Korean popular music groups such as BTS and Blackpink also continue to capture the imaginations of mainly young music lovers across

57 David Colquhoun and Steven Salzberg typify this group of critics. See Colquhoun and Novella 2013; Salzberg 2018.

$5^{8} \quad$ For Taiwan, see Taipei Times 2020.

59 Rosenberg 2007. 
the world. ${ }^{60}$ If Koreans have achieved success in exporting cultural products such as K-pop, I suggest that we also pay attention to Korean healing practices.

Doctors of Korean medicine neither decry nor promote the diminishment of biomedicine's important role but simply ask that they be allowed a place at the table. In a political moment when some political leaders on the global stage stake their authority on bombast and drumbeating, Korean medicine doctors have, as most healthcare workers in the world have done in 2020, worked quietly and humbly. Although, their voices were barely heard in the maelstrom and cacophony that was 2020, I argue that we need to heed their messages. Ha tells us that "I will be there immediately in any epidemic in Korea. I hope to help patients. My confidence continues to be based on our medicine's effectiveness." Yoon argues: "Measured and considered use of traditional medicine can be beneficial for the world." Compassion for suffering patients demands we expand our healthcare tools beyond the narrow frame of biomedicine as arbiter. As I write in December 2020, Korea has entered a new phase of a surge in coviD-19 cases. The telemedicine clinic in Seoul is busy with a new wave of patients. The doctor's experiences in this resurgence of the virus in Korea await analysis. However, the example of Korean medicine in Covid-19 in the first half of 2020 provides a clear case of effective healthcare beyond the narrow limitations of biomedicine that became so evident in $202 \mathrm{O}$.

\section{Acknowledgments}

I would like to express my gratitude to Taewoo Kim, Eunkyung Han, and Stephan Taehyung Lee who pointed me to data and doctors to interview. Additional thanks to Taewoo for his detailed comments on my initial framing and first draft. Thanks too to Marta Hanson who made detailed comments on my draft. Thanks also to the anonymous reviewers for their helpful comments. This research was supported by the Brain Pool Program funded by the Ministry of Science and ICT through the National Research Foundation of Korea, grant no. $2 \mathrm{O}_{2} \mathrm{OH} \mathrm{H}_{3} \mathrm{D}_{3} \mathrm{Ao} 0408157 \mathrm{O}$.

\section{About the Author}

James Flowers is a Brain Pool Program research fellow in Kyung Hee University, South Korea, and a practitioner of Chinese medicine. He holds a $\mathrm{PhD}$ in the

6o Boman 2019 . 
history of medicine from Johns Hopkins University School of Medicine and an MA in international studies from the University of Technology Sydney.

\section{Bibliography}

\section{Primary Sources}

А КОМ (Association of Korean Medicine). 2020. K'oronabairǒsŭgamyǒmjŭng-19 Hanŭijinryu kwǒngoan [Guidelines on Treating CoviD-19]. March. Unpublished internal document, received by email and cited with permission from Аком.

Cao Desheng. 2020. "Xi Presents Medals to COVID Fighters." China Daily, September 9, 2020. https://www.chinadaily.com.cn/a/2020og/og/WS5f58oa54a310675eafc58594 .html.

Chen Keji 陳可冀, ed. 2006. Qinggong yian yanjiu 清宮醫案研究. Beijing: Ancient Chinese Medical Texts Publishing House.

Hanŭi Sinmun. 2020. "Yangbang Chungsim Kamyombyong Chegyesǒ Hanŭigyedo 'Hal su itda'r ǔl chǔngmyǒng." September 29, 2020. http://akomnews.org/bbs/board. php?bo_table=news\&wr_id=41563.

"Hubei Province Integrated Chinese/Western Medicine Hospital Critical Viral Respiratory Disease Formulas." 2020. https://www.ccaom.org/ccaom/Coronavirus _Disease_(COVID-19)_Member_Resources.asp.

Kang, Dake. 2020. "In China's Xinjiang, Forced Medication Accompanies Lockdown." Washington Post, August 31, 2020. https://www.washingtonpost.com/world/asia _pacific/xinjiang-govt-forces-unproven-medicine-on-people-in-lockdown/2020/ o8/31/77a997c6-eb3f-11ea-bdo8-1b1o132b458f_story.html.

Kim Ch'un-ho. 2020. “Hanǔihyǒp p'osǔtǔ-k'orona 19 Hanǔiyak yǒghal mit hwalyongbangan gukhoe p'orǒm kaejoe." Minjok Ǔihak Sinmun, June 11, 2020. http://www .mjmedi.com/news/articleView.html?idxno=50910.

Moon Jae-in. 2020. “Jung Eun-kyeong." Time, September 22, 2020. https://time.com/ collection/10o-most-influential-people-2020/5888333/jung-eun-kyeong/.

PRC SCIO (State Council Information Office of the People's Republic of China). 2020.

Fighting COVID-19: China in Action. June 2020. http://english.scio.gov.cn/white papers/2020-06/o7/content_76135269.htm.

Taipei Times. 2020. "Virus Outbreak: Virus Treatments Show Promising Results: NRICM." May 16, 2020. https://www.taipeitimes.com/News/taiwan/archives/2020/ 05/16/2003736501.

TK. 2020. "The President's Summer Reading." The Blue Roof, September 1, 2020. https:// www.blueroofpolitics.com/p/the-presidents-summer-reading/.

wHo (World Health Organization). 2004. SARS: Clinical Trials on Treatment Using a Combination of Traditional Chinese Medicine and Western Medicine: Report of 
the WHO International Expert Meeting to Review and Analyse Clinical Reports on Combination Treatment for SARS, 8-10 October 2003, Beijing, People's Republic of China. Geneva: wHо.

Xinhua News. 2020a. "TCM Used in Treating 92 pct COVID-19 Cases in China: White Paper." June 7, 2020. http://www.xinhuanet.com/english/2O2O-o6/o7/c_139120554 .htm.

Xinhua News. 2020b. "TCM Should Be Integrated into National Public Health System: Expert." June 16, 2020. http://www.xinhuanet.com/english/2O2O-o6/16/c_139142328 .htm.

\section{Secondary Sources}

Allen, Colin, and David Finegold. 2020. "How to Use Precision Medicine to Personalize COVID-19 Treatment According to the Patient's Genes." The Conversation, September 2, 2020. https://theconversation.com/how-to-use-precision-medicine -to-personalize-covid-19-treatment-according-to-the-patients-genes-142142.

Baker, Don. 1990. "Sirhak Medicine: Measles, Smallpox, and Chŏng Tasan." Korean Studies 14: 135-66.

Bent, Stephen, Thomas Tiedt, Michelle Odden, and Michael Shlipak. 2003. "The Relative Safety of Ephedra Compared with Other Herbal Products." Annals of Internal Medicine 138, no. 6 (March 18): 468-72.

Boman, Björn. 2019. "Achievement in the South Korean Music Industry." International Journal of Music Business Research 8, no. 2 (October): 6-26.

Bretelle-Establet, Florence. 2020. "Science, Demons, and Gods: The Battle Against the COVID-19 Epidemic." Centaurus 62, no. 2 (May): 344-53.

Cha, Victor. 2020. "Asia's COVID-19 Lessons for the West: Public Goods, Privacy, and Social Tagging." The Washington Quarterly 43, no. 2: 33-5o.

Choi, Jun-Yong, and Myungsoo Joo. 2020. "The Pathogenesis and Alternative Treatment of SARS-CoV2." Integrative Medicine Research 9:1-2.

Colquhoun, David, and Steven Novella. 2013. "Acupuncture is Theatrical Placebo." Anesthesia and Analgesia 116, no. 6 (June): 136o-63.

Couzin-Frankel, Jennifer. 2020. "From 'Brain Fog' to Heart Damage: COVID-19's Lingering Problems Alarm Scientists." Science Magazine, July 31, 2020. https:// www.sciencemag.org/news/2020/o7/brain-fog-heart-damage-covid-19-s-lingering -problems-alarm-scientists.

DiMoia, John. 2020a. "Remembering MERS in South Korea: Mobilizing Experience of Epidemic Disease." Journal of the History of Ideas Blog, May 4, 2020. https://jhiblog .org/2020/05/o4/history-mers-south-korea-covidig-response/.

DiMoia, John. 2020b. "Weighing Privacy Concerns: South Korean Public Health during Covid-19." Fieldsights (blog of the Society for Cultural Anthropology), "Hotspots" section, June 23, 2020. https://culanth.org/fieldsights/weighing-privacy -concerns-south-korean-public-health-during-covid-19. 
Flowers, James. 2016. "Reconfiguring East Asian Modernity: How the Unorthodox Healer Stone Gorge Yi Connected Supporting the Heart with Strengthening Korea as a Civilisation." Asian Medicine: Tradition and Modernity 11, no. 1: 61-99.

Flowers, James. 2020. "Hanbang Healing for the World: The Eastern Medicine Renaissance in 193 os Japan-Ruled Korea." Social History of Medicine, special issue on East Asian medicine, edited by Dora Vargha. https://doi.org/10.1093/shm/hkz123. Gordon, Andrew. 2020. "Historical Context for COVID 19 Policies in Japan and Asia (2).” Tokyo College Blog, June 11, 2020. https://www.tc.u-tokyo.ac.jp/en/weblog/1847/. Greene, Jeremy, Victor Braitberg, and Gabriella Bernadett. 2020. "Innovation on the Reservation: Information Technology and Health Systems among the Papago Tribe of Arizona, 1965-1980." Isis 111, no. 3 (September). https://www.journals.uchicago .edu/doi/10.1086/710802.

Grisafi, John. Forthcoming. "A Marginal Religion and COVID-19 in South Korea: Shincheonji, Public Discourse, and the Shaping of Religion." Nova Religio.

Hanson, Marta. 2020. "From Sick Man of Asia to Sick Uncle Sam." Current History 119, no. 817 (September): 241-44. https://doi.org/10.1525/curh.2020.119.818.241.

Harrison, Mark. 2020. "COVID-19 remapping East Asian Modernity." Thesis Eleven (August 12).

Jin, Zhao. 2020a. "Approaching Covid-19 as Damp Toxin: Wu Youke and Xue Xue Take Us Back To School." The Lantern 17, no. 2a (March): 14-21.

Jin, Zhao. 202ob. "The Use of Chinese Medicine in Treating COVID-19." Online presentation to Johns Hopkins University, May, 2020. https://www.youtube.com/ watch? $\mathrm{v}=$ PpifdpWYe6I\&feature=youtu.be\&fbclid=IwAR3vopQQNg73daqD8J MQ_sNeuouOwDY-tEZ9CcpG5c-TifmUCx7AoiNd8-k.

Kang, Jaeho. 2020. "The Media Spectacle of a Techno-City: COVID-19 and the South Korean Experience of the State of Emergency." Journal of Asian Studies 79, no. 3 (August): 589-98.

Kim, Dong-su, Hongmin Chu, Baek Ki Min, YoungJoo Moon, Seogjun Park, Kwangho Kim, Shin-Hyeok Park, Young-Don Kim, Mideok Song, and Gun-hee Choi. 2020. "Telemedicine Center of Korean Medicine for Treating Patients with COVID-19: A Retrospective Analysis." Integrative Medicine Research 9: 1-5.

Kim Du-jong. 1981. Hanguk ŭihaksa 韓國醫學史. Reprint. Seoul: Tamgu Publishing.

Kim Sang-hyun, Jang Woo-chang, Baik You-sang, Lyu Jeong-ah, and Jeong Chang-hyun. 2015. "Pyŏkyŏksinbang ŭi Dokyǒk e Taehan Koch'al" [A Study on "Dokyeok" of Byeokyeoksinbang]. Journal of Korean Medicine Classics 28, no. 2: 33-45.

Kim, Taewoo. 2016. "Tradition on the Move: Emerging Acupuncture Practices in Contemporary South Korea." Asian Medicine: Tradition and Modernity 11: 133-59.

Kim, Taewoo. 2017. "Cultivating Medical Intentionality: The Phenomenology of Diagnostic Virtuosity in East Asian Medicine." Culture, Medicine, and Psychiatry 41: 75-93. 
Kwon, Chan-Young. 2020. "Mental Health in COVID-19 Era and Use of Mind-Body Medicine in the Telemedicine Center." Unpublished lecture delivered to the "Toward Integrative Medicine in Post COVID-19 Era" online conference, December 15, 2020. https://www.youtube.com/watch?v=-9G3ViLwsJQ.

Kwon, Chan-Young, and Boram Lee. 2020. "Characteristics of Individuals Receiving Telemedicine Mental Health Services Using Mindfulness: Cases in South Korea During the COVID-19 Pandemic." Letters to the Editor. Asian Journal of Psychiatry 54. http://www.sciencedirect.com.ssl.openlink.khu.ac.kr:808o/science/article/pii/ S1876201820304871.

Kwon, Seungwon, Heebum Chung, Younggun Kang, Insoo Jang, Jun-Yong Choi, In Chul Jung, Jae-Woo Park, and Hyangssok Lee. 2020. "The Role of Korean Medicine in the Post-COVID-19 Era: An Online Panel Discussion; Part 1, Clinical Research.” Integrative Medicine Research 9: 1-6.

Lee, Beom-Joon. 2020. "Management of Mild COVID-19 Patients with Telemedicine of Traditional Korean Medicine: A Retrospective Observational Case Series." Unpublished lecture delivered to the "Toward Integrative Medicine in Post COVID-19 Era" online conference, December 15, 2020. https://www.youtube.com/ watch?v=-9G3ViLwsJQ.

Lee, Eun-Kyoung. 2020. "Telemedicine and the Use of Korean Medicine with COVID-19 Patients in South Korea." Unpublished lecture delivered to the "Toward Integrative Medicine in Post COVID-19 Era" online conference, December 15, 2020. https:// www.youtube.com/watch?v=-9G3ViLwsJQ.

Lee, MR. 2011. "The History of Ephedra (ma-huang)." Journal of the Royal College of Physicians of Edinburgh 41, no. 1 (March): 78-84.

Li, Qingwei, Han Wang, Xiuyang Li, Yujiao Zheng, Yu Wei, Pei Zhang, Qiyou Ding, Jiaran Lin, Shuang Tang, Yikun Zhao, Linhua Zhao, and Xiaolin Tong. 2020. "The Role Played by Traditional Chinese Medicine in Preventing and Treating COVID-19 in China." Frontiers in Medicine (July 10): 1-8.

Luo, Hua, Yan Gao, Jian Zuo, Siyuan Zhang, Hanbin Chen, Qiao Liu, Dechao Tan, Yan Han, Yonghua Zhao, and Shengpeng Wang. 2020. "Reflections on Treatment of COVID-19 With Traditional Chinese Medicine." Chinese Medicine 15, no. 94. https:// cmjournal.biomedcentral.com/track/pdf/10.1186/s13020-020-00375-1.pdf.

Ma, Eun Jeong. 2010. “The Medicine Cabinet: Korean Medicine Under Dispute." East Asian Science, Technology and Society 4, no. 3: 367-82.

Ochs, Shelley, and Thomas Avery Garran, trans. and ed. 2020. Chinese Medicine and COVID-19: Results and Reflections from China. Beijing: Passiflora Press.

Park, June, and Eunbin Chung. 2021. "Learning from Past Pandemic Governance: Early Response and Public-Private Partnerships in Testing of COVID-19 in South Korea." World Development 137. https://www.ncbi.nlm.nih.gov/pmc/articles/PMC7500944/. 
Park, Ki-Joo, and Yang Donghyu. 2007. "The Standard of Living in the Chosŏn Dynasty Korea in the 17 th to the 19th Centuries." Seoul Journal of Economics 20, no. 3: 297-332. Park, Sunju, Dae-Hyun Hahm, Myungsoo Joo, Kyongnim Kim, Sunoh Kwon, Hoyoung Choi, and Hyangsook Lee. 2020. "The Role of Korean Medicine in the post-COVID-19 Era: An Online Panel Discussion; Part 2, Basic Research and Education." Integrative Medicine Research 9: 1-6.

Reischauer Covid-19 Task Force (Edwin O. Reischauer Center for East Asian Studies COVID-19 Policy Research Task Force). 2020a. "The COVID-19 Crisis: Policy Lessons from East Asia." April 2020. https://www.reischauercenter.org/reischauercenter/ wp-content/uploads/The-COVID-19-Crisis-Policy-Lessons-from-East-Asia-FINAL .pdf.

Reischauer COVID-19 Task Force. 2020b. "East Asia in the Post-COVID-19 World." May 2020. https:/www.reischauercenter.org/reischauercenter/wp-content/uploads/ East-Asia-Post-COVID-19-World_FINAL_May.pdf.

Rosenberg, Charles E. 2007. "Alternative to What? Complementary to Whom? On the Scientific Project in Medicine." In Our Present Complaint: American Medicine, Then and Now, edited by Charles Rosenberg, 113-32. Baltimore, MD: Johns Hopkins University Press.

Salzberg, Steven. 2018. "WHO Endorses Traditional Chinese Medicine: Expect Deaths to Rise." Forbes, October 1, 2018. https://www.forbes.com/sites/stevensalzberg/2018/ 10/o1/who-endorses-tcm-expect-deaths-to-rise/\#1ea6c53d6418.

Scheid, Volker, Dan Bensky, Andrew Ellis, and Randall Barolet. 20o9. Chinese Herbal Medicine: Formulas and Strategies. 2nd ed. Seattle, WA: Eastland Press.

Setton, Mark. 1997. Chŏng Yagyong: Korea's Challenge to Orthodox Neo-Confucianism. Albany: State University of New York Press.

Shin, Dongwon. 2010. "Hanguk Chŏngŭndae Ǔihaksa Yŏngu Tonghyang." Korean Journal of Medical History 19, no. 1 (June): 1-44.

Shin, Dongwon. 2014. "Measures Against Epidemics During Late 18th Century Korea: Reformation or Restoration?” Extrême-Orient, Extrême Occident 37: 91-110.

Tilley, Helen. 2020. "How to Make Sense of 'Traditional (Chinese) Medicine' in a Time of Covid-19: Cold War Origin Stories and the WHO's Role in Making Space for Polyglot Therapeutics." Somatosphere, May 25, 2020. http://somatosphere.net/ 2020/tcm-covid-19.html/.

Varlik, Nukhet. 2020. "The Plague That Never Left: Restoring the Second Pandemic to Ottoman and Turkish History in the Time of COVID-19." New Perspectives on Turkey 1: 1-14. https://doi.org/10.1017/npt.2020.27.

Yoo, Theodore Jun. 2016. It's Madness: The Politics of Mental Health in Colonial Korea. Berkeley: University of California Press. 